\title{
NURSING ASSISTANCE TO PATIENTS WITH BREAST CANCER
}

Marina E. Rocha', Daniel Jesus², Ludiayne M. do Carmo², Lorrany L. Rodrigues², Michelle R. Oliveira², Tatiana F. Silva², Verônica S. Silva², Lorena T. Quirino ${ }^{3}$

${ }^{1}$ Universidade Federal de Goiás - Goiânia (GO), Brazil.

${ }^{2}$ Faculdade União de Goyazes - Trindade (GO), Brazil.

${ }^{3}$ Pontifícia Universidade Católica de Goiás - Goiânia (GO), Brazil.

Objective: To report the importance and nursing assistance regarding the prevention and early detection of breast cancer. Methodology: The present study was developed through a non-systematized bibliographic research. Articles, books, and data on the subject addressed were searched. Outcome: There is no single cause for breast cancer because several factors, such as being a woman and getting older, are the main factors that increase the risk. Other factors such as obesity and overweight, mainly after menopause, frequent exposure to ionizing radiation, first menstruation before 12 years, no children, first pregnancy after 30 years old, have not breastfed, and family history of breast and ovary cancer, especially in first-degree relatives before age 50, only increase the risk of developing breast cancer even more. According to INCA in Brazil, it is estimated that 59,700 new cases of breast cancer were diagnosed each year in the 2018-2019 biennium, with an estimated risk of 56.33 cases per 100,000. Knowing this in our professional work we must guide and ensure preventive actions aimed at prioritizing the early detection of abnormalities in the breast. Conclusion: We found that in women the cancer with the highest incidence and prevalence is breast cancer. Therefore extremely important to the effective participation of nurses in relation to support, information, stimulating the patient to start treatment as soon as possible, healing doubts regarding the involvement, and family commitment to it, since low self-esteem and family support is still a great challenge for the multi-professional team. Knowing this the Nurse must consider and evaluate this patient in a holistic way and not only focused on the illness that the patient is affected, in front of this offering humanized assistance. 